\title{
A Study on the Prediction of Compressive Strength of M20 Grade Concrete using Reclaimed Rubber and Silica fume
}

\author{
C. Kanmalai Williams \\ Department of Civil Engineering \\ St.Peter's University, Chennai, Tamil Nadu, India \\ P.Partheeban \\ Department of Civil Engineering \\ St.Peter's College of Engineering \& Technology, Chennai, Tamil Nadu, India
}

\begin{abstract}
Everyday the demand for building materials is increasing through out the world. This study is focused on the prediction of compressive strength of $\mathbf{M 2 0}$ grade concrete cubes and cylinders by partially replacing coarse aggregates with reclaimed rubber and cement with silica fume in various proportions. The objective of this research is to determine the optimum replacement of Reclaimed Rubber (RR) and Silica Fume(SF) in concrete experimentally and analytically. In the preliminary study 81 cubes were cast replacing cement with silica fume in 3 percent increments. The main study was carried out by casting another 81 cubes replacing cement with optimum SF and with various proportions of RR. Genetic algorithm was used to predict the compressive strength of concrete. 1000 sets were taken and 100 iterations were run during training of GA models. Experimental results revealed that the optimum replacement of SF and RR as 12 percent and 9 percent respectively. Moreover the variation between experimental and analytical results were found to be less than 10 percent in both cubes and cylinders.
\end{abstract}

Keywords - Silica Fume; Compressive Strength; Reclaimed Rubber; Genetic Algorithm; M20 grade

\section{INTRODUCTION}

Cement concrete gives the required strength and durability to the structure. The production of ordinary Portland cement has increased greatly during the last decades especially in emerging and developing countries. In the recent years waste tires have been recycled and used in concrete as a replacement for aggregates thereby reducing the demand for natural aggregates and solving the problem of solid wastes in landfill to a greater extent. Silica fume and reclaimed rubber were used partially replacing cement and coarse aggregates in this research work. An experimental study on waste rubber tire concrete and Silica fume replacing fine aggregate and cement for M25 grade concrete indicated that there is a reduction in compressive and split tensile strengths and an increase in flexural strength as the rubber content increases [1].

Concrete mix design is a process that uses the recommended code and determines the mix proportion for the ingredients of concrete. In this research IS 10262-2009 is being used to calculate the mix proportion. Early prediction of compressive strength enables to know the properties of concrete and its probable weakness which helps to continue or discontinue the construction process[2]. The aim of this study is to determine the concrete strength through experimental methods and compare the results with those obtained analytically using genetic programming. The basic concept of genetic algorithm is designed to simulate processes in natural system necessary for evolution[3].

The replacement of natural aggregates with rubber aggregates tends to reduce the compressive strength of concrete. Previous study show that the reduction in strength was nearly 60 percent for concrete at early age compared to 90 days strength of concrete for similar replacement percent of rubber aggregates in concrete mix.It was generally observed that the compressive strength of concrete reduced with an increase in the rubber particles in concrete. [4].

\section{LITERATURE REVIEW}

Experiments performed with various percentages of Silica fume replacing cement with a water cement ratio of 0.5 revealed that the optimum compressive strength was obtained at 20 percent replacement of cement by silica fume at 
all age levels ( 24 hours, 7 and 28 days). Test results showed that compressive strength of $100 \mathrm{~mm}$ cubes are higher than $150 \mathrm{~mm}$ cubes at all age levels[5].It was observed that predicted compressive strength values are very near to the experimentally obtained values.To further test the efficacy and reliability of the models, the in situ compressive strength data at curing age of 28 days has been used in the study[6].

Another research confirmed that optimum silica fume replacement percentage for 28- day's strength of concrete ranged from 10 to 20 percent. Cement replacement up to 10percent with silica fume leads to increase in compressive strength for M30 grade of concrete and improves the mechanical properties of concrete. In this study suitability of silica fume has been discussed by replacing cement with silica fume at varying percentage and the strength parameters were compared with conventional concrete[7].

In a research on compressive strength of silica fume concrete it was found that the compressive strength increased with increase in percentage replacement of silica fume with 5 and 10 percent and then gradually decreased with 15 percent replacement. It also revealed that the compressive and tensile strength of concrete increased with age [8].

An analysis on strength prediction of crumb rubber concrete showed that there was a strong correlation between increasing rubber content and compressive strength reduction. The reduction in compressive strength reached 70 percent at 25 percent rubber content. The proposed model had the least scattering in its predictions compared to similar previous models [9].

While conducting a study on the mechanical characteristics of rubberized concrete which was treated with carbon tetrachloride and sodium hydroxide it was found treating rubber with these chemicals and mixing it in concrete did not have a significant effect on the compressive strength of concrete[10].

Studies showed that the maximum amount of rubber to be used in the concrete mix should be less than $20 \%$. Other studies showed that the concrete strength improved substantially by conditioning the rubber before the mixing process. Sodium Hydroxide $(\mathrm{NaOH})$ is proven to be effective in conditioning the tire rubber by improving the bonding strength between the rubber particles and the concrete paste[11].

It was observed that compressive strength of concrete mix having a higher percent replacement of rubber aggregates is more than the mix having a lower replacement of aggregates. It was due to its workability, increase in the proportion of gravels and the wide range of aggregate size in the concrete mix[12].

Results show that evolutionary polynomial regression models provide very accurate predictions for strength parameters of rubber concrete. The developed models present a structured and transparent representation of the system allowing a physical interpretation of the problem that gives the user an insight into the relationship between strength and various parameters[13].

\section{MATERIALS USED}

The cementitious material used in concrete was Ordinary Portland cement (53 grade). Clean dry river sand and hard granite broken stones of $20 \mathrm{~mm}$ size were used in the concrete mix. Reclaimed rubber replaced conventional coarse aggregates. SF replaced cement which was used as an admixture in the concrete mix to enhance the compressive strength. M20 grade of concrete was prepared with a water - cement ratio of 0.3 . The concrete mix was designed as per IS 10262-2009 and the mix proportion was found to be 1:1.85:3.13:0.5.

Cement is binding material in the cement concrete which fills up voids existing in the fine aggregate and makes the concrete impermeable and provides strength to concrete on setting and hardening.

Aggregate is commonly considered inert filler, which accounts for 60 to 80 percent of the volume and 70 to 85 percent of the weight of concrete [14]. The shape, texture, size gradation, moisture content, specific gravity, reactivity, soundness and bulk unit weight along with the water/cement ratio determine the strength, workability, and durability of concrete. The shape and texture of aggregate affects the properties of fresh concrete more than hardened concrete.

Fine aggregate is one of the ingredients of the concrete mix. The size of fine aggregate is less than $4.75 \mathrm{~mm}$. Table 1 shows the properties of fine aggregates such as specific gravity, water absorption and fineness modulus. 
Table -1 Physical Properties of Fine Aggregate

\begin{tabular}{|c|c|c|}
\hline S. No & Name of Test & Result \\
\hline 1 & Specific Gravity & 2.6 \\
\hline 2 & Water Absorption & $2.4 \%$ \\
\hline 3 & Fineness modulus & 3.5 \\
\hline
\end{tabular}

Coarse aggregate is an ingredient of concrete mix which is being replaced partially by reclaimed rubber. Table 2 shows the test results of coarse aggregates such as specific gravity, water absorption and fineness modulus.

Table -2 Physical Properties of Coarse Aggregate

\begin{tabular}{|c|c|c|}
\hline S. No & Name of Test & Result \\
\hline 1 & Specific Gravity & 2.67 \\
\hline 2 & Water Absorption & $0.5 \%$ \\
\hline 3 & Fineness modulus & 3.5 \\
\hline
\end{tabular}

The replacement of natural aggregates with rubber aggregates tends to reduce the density of the concrete. This reduction is attributable to the lower unit weight of rubber aggregate compared to ordinary aggregate. The unit weight unit weight of rubberized concrete mixtures decreases as the percentage of rubber aggregate increases. Reclaimed rubber has been obtained from Inter City Enterprises, Chennai and cut to the required shape and size(Fig.1). Table 3 shows the test results of reclaimed rubber such as specific gravity, density, water absorption etc.,

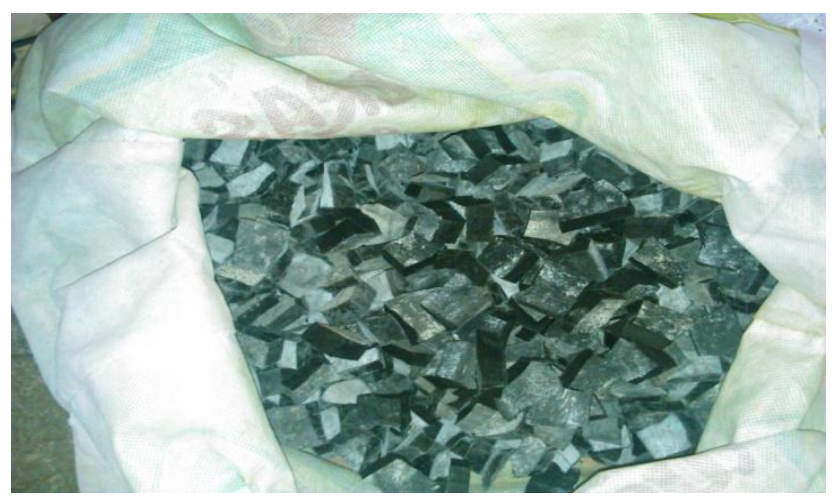

Figure 1. Reclaimed Rubber

Table -3 Properties of Reclaimed Rubber

\begin{tabular}{|c|c|c|}
\hline S. No & Description & Values \\
\hline 1 & Ash Content & $5.43 \%$ \\
\hline 2 & Density & $1.123 \mathrm{~g} / \mathrm{cc}$ \\
\hline 3 & Tensile Strength & $17.71 \mathrm{~kg} / \mathrm{cm}^{2}$ \\
\hline 4 & Specific Gravity & 1.25 \\
\hline 5 & Water Absorption & $8.5 \%$ \\
\hline
\end{tabular}

Silica fume is a puzzalonic material which is used to strengthen the transition zone in concrete. In high performance concrete 7 percent of silica fume and 0.5 percent of cellulose fiber gives an optimum compressive strength beyond which the strength decreases [15]. The physical properties of silica fume is given in Table 4. 
Table -4 Properties of Reclaimed Rubber

\begin{tabular}{|c|c|c|}
\hline S.No & Description & Values \\
\hline 1 & Physical state & Micronized powder \\
\hline 2 & Odor & Odorless \\
\hline 3 & Appearance & White Color powder \\
\hline 4 & Pack density & 0.76 gm./cc \\
\hline 5 & Ph of 5\% solution & 6.9 \\
\hline 6 & Specific gravity & 2.63 \\
\hline 7 & Moisture & $0.058 \%$ \\
\hline
\end{tabular}

\section{MethodOLOGY}

The concrete mix was prepared based on the mix design in a mixer machine. Moulds of size $150 \times 150 \times 150 \mathrm{~mm}$ for cubes were used to cast the samples. The concrete batch is mixed on a water tight, non-absorbent steel platform with a shovel, trowel and similar suitable equipment using the following procedure. The ingredients of concrete are mixed in the required proportion in a concrete mixer machine after adding the required quantity of water. The mixing is continued until concrete appears to be homogenous and has the desired consistency. After mixing the cube moulds are filled in layers, compacted and allowed to harden for a period of 24 hours (Fig.2) All the specimens are demoulded and immersed in a curing tank to attain the required strength (Fig.3)
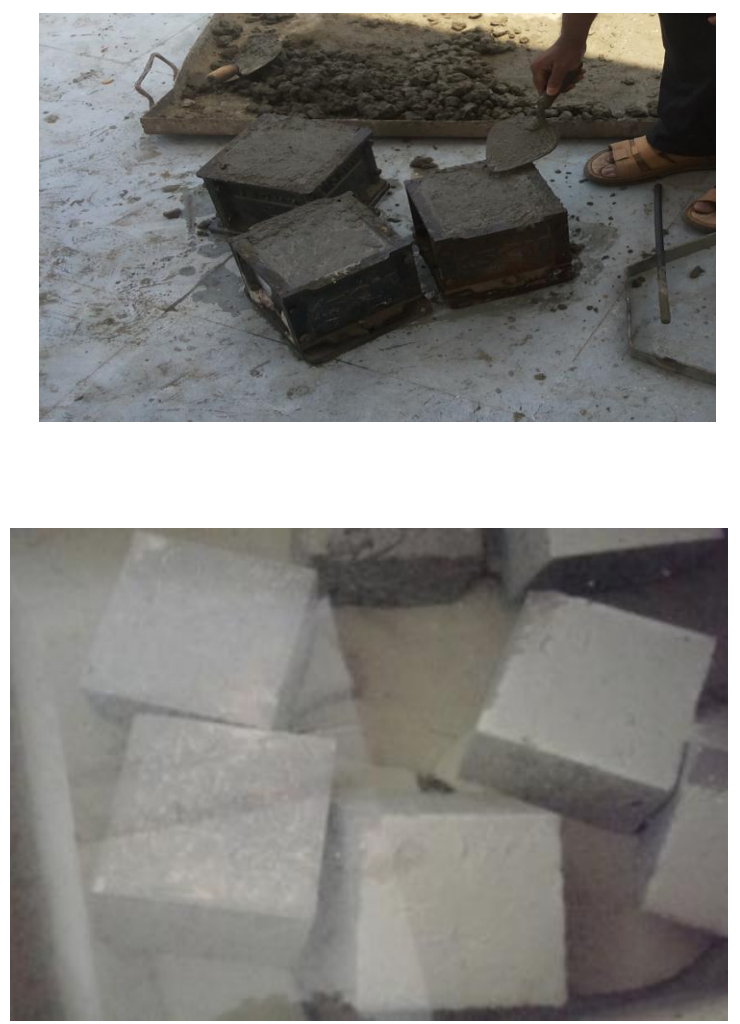

Figure 3. Curing of Cube Samples

In the main study reclaimed rubber replaces coarse aggregates in increments of 3 percent from zero up to 24 percent in concrete along with optimum SF percent obtained. Cubes were cast and cured for 7,14 and 28 days and tested for compressive strength in Universal Testing Machine (UTM) which has a capacity of 50 tons (Fig. 4). 


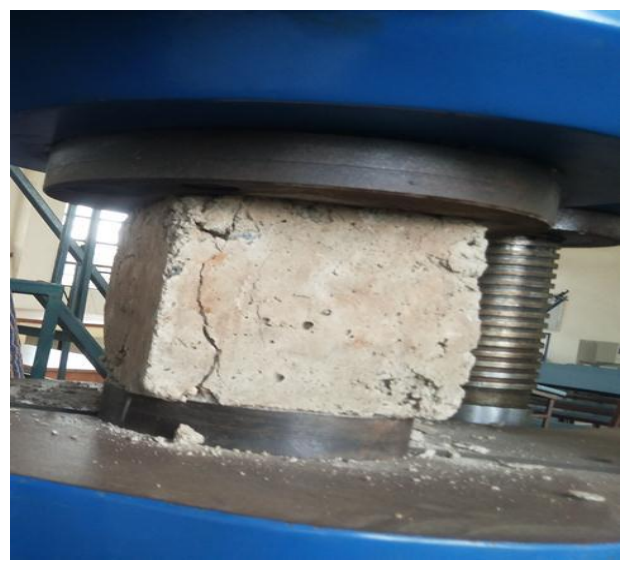

\section{Figure 4. COMPRESSIVE STRENGTH TeSt ON CUBES USING UTM}

Testing of hardened concrete helps to achieve the required quality of concrete with respect to strength and durability. The rate of loading on the specimens were monotonic in nature. The above test was conducted to find the maximum load carrying capacity of the specimen.

Genetic algorithm work with a set of individuals representing possible solutions of the task. The selection of individuals is performed by survival of the fittest. The selection principle is applied by using a criterion giving an evaluation for the individual with respect to the desired solution. The best suited individuals create the next generation. In this recombination type the parents exchange the corresponding genes to form a child. The cross over can be single or multi-point figure. For the recombination a bit Mask is used (Fig.5). The equations describing the process are :

$C_{1}=$ Mask $_{1} \& P_{1}+$ Mask $_{2} \& P_{2}$

$C_{2}=$ Mask $2 \& P_{1}+$ Mask $1 \& P_{2}$

$\mathrm{P}_{1}, \mathrm{P}_{2}$ - parent's chromosomes;

$\mathrm{C}_{1}, \mathrm{C}_{2}$ - children's chromosomes (offspring individuals);

Mask1, Mask2 - bit masks (Mask2 = NOT (Mask1)) \& - bit operation "AND”.

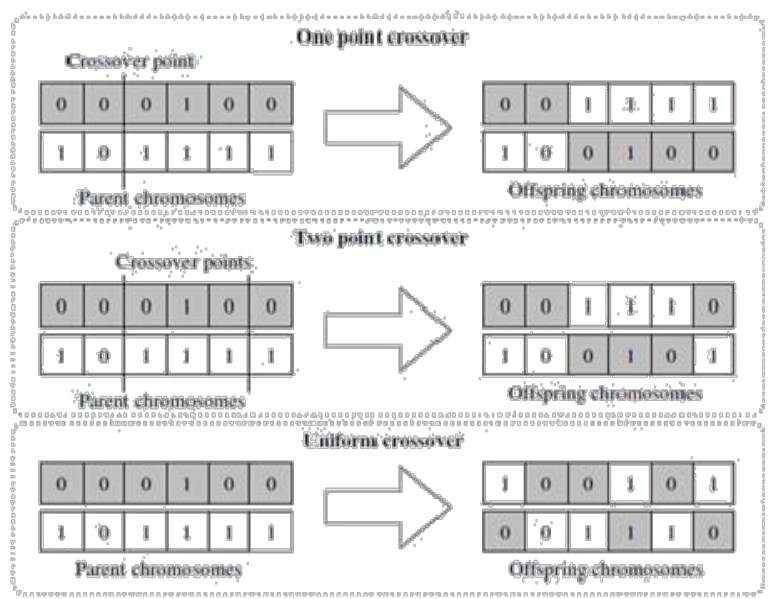

Figure 5. Crossover with Bitmask

The mathematic description of this crossover is:

$C_{1}=\gamma \cdot P_{1}+(1-\gamma) \cdot P_{2}$

$C_{2}=(1-\gamma) \cdot P_{1}+\gamma \cdot P_{2}$ 
$\gamma=(1+2 \cdot \alpha) \cdot r-\alpha$

$\mathrm{P}_{1}, \mathrm{P}_{2}$ - chromosomes of the parents;

$\mathrm{C}_{1}, \mathrm{C}_{2}-$ chromosomes of the children (offspring individuals);

$\alpha$ - exploration coefficient - user defined $(\alpha \geq 0)$;

$\mathrm{r}$ - random number between 0 and 1 ;

Mutation means random change of the value of a gene in the population (Fig.6). The chromosome, which gene will be changed and the gene itself are chosen by random as well and Fig.7 shows the mutation process in genetic algorithm.

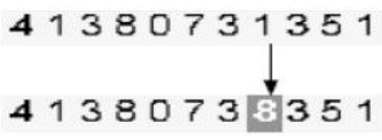

Figure 6. Mutation in a Chromosome

\begin{tabular}{l}
\begin{tabular}{|c|c|c|c|c|c|c|c|c|c|c|c|}
\hline 1 & 1 & 0 & 1 & 0 & 0 & 0 & 1 & 1 & 1 & 0 & 1 \\
\hline 1 & Before mutation \\
\hline 1 & 1 & 0 & 0 & 0 & 0 & 0 & 1 & 1 & 1 & 0 & 1 \\
\hline
\end{tabular} \\
\hline
\end{tabular}

Figure 7. Mutation in Genetic Algorithm

The Evolutionary Algorithm (EA) holds a population of individuals (chromosomes), which evolve my means of selection and other operators like crossover and mutation. Every individual in the population gets an evaluation of its adaptation (fitness) to the environment. The selection chooses the best gene combinations (individuals), which through crossover and mutation should drive to better solutions in the next population. The most often used schemes of GA is shown in flow chart as shown in Fig.9. In most of the algorithms the first generation is randomly generated, by selecting the genes of the chromosomes among the allowed alphabet for the gene. It is possible to stop the genetic optimization by:

$>$ Identifying the value of the function of the best individual is within defined range around a set value.

$>$ Maximal number of iterations which is the most widely used stopping criteria.

$>$ During crossover the individuals chosen by selection recombine with each other and new individuals will be created.

$>$ Mutation is done by means of random change of some of the genes.

The elite individuals chosen from the selection are combined with those who passed the crossover and mutation, and form the next generation.

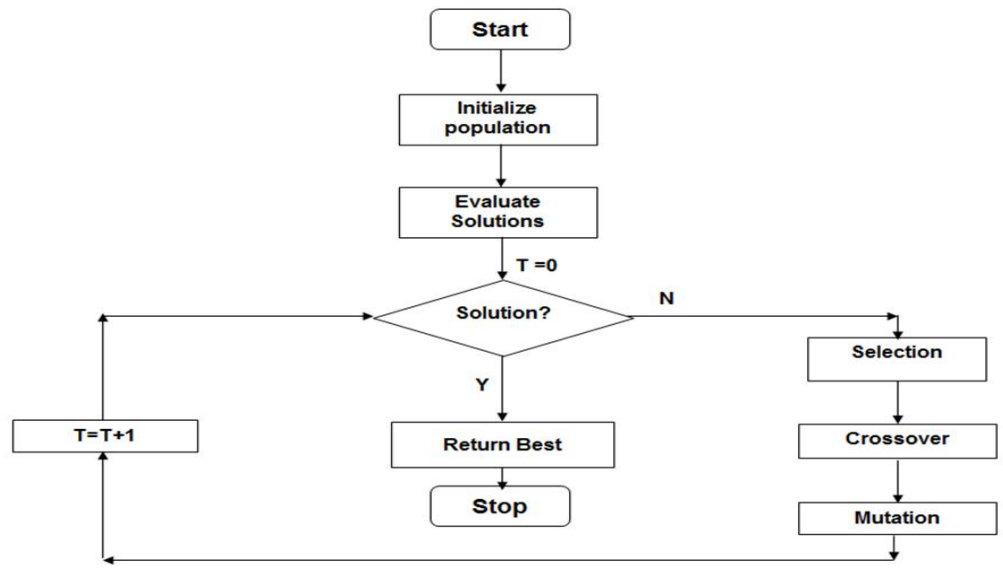

Figure 8. Flow Chart showing Scheme of EA

\section{IV.RESULTS AND DISCUSSION}

The maximum load is obtained with the aid of a UTM. Table 6 shows the compressive strength test results of M20 grade concrete replacing cement with different proportions of silica fume. 
Table 6: Test Results of M20 Grade Concrete

\begin{tabular}{|c|c|c|c|c|}
\hline \multirow{2}{*}{ S.NO } & \multirow{2}{*}{ SF (\%) } & \multicolumn{3}{|c|}{ Average compressive strength $\left(\mathbf{N} / \mathbf{m m}^{\mathbf{2}}\right)$} \\
\cline { 3 - 5 } & & ${\mathbf{7}^{\text {th }}}^{\mathbf{n}} \mathbf{d a y}$ & $\mathbf{1 4}^{\text {th }} \mathbf{d a y}$ & $\mathbf{2 8}^{\text {th }} \mathbf{d a y}$ \\
\hline 1 & 0 & 13.89 & 17.36 & 21.22 \\
\hline 2 & 3 & 15.76 & 19.7 & 25.36 \\
\hline 3 & 6 & 17.52 & 21.9 & 28.10 \\
\hline 4 & 9 & 18.2 & 22.5 & 30.0 \\
\hline 5 & 12 & 19.6 & 24.22 & 32.5 \\
\hline 6 & 15 & 14.7 & 20.45 & 26.6 \\
\hline 7 & 18 & 12.1 & 16.4 & 22.3 \\
\hline 8 & 21 & 10.5 & 14.2 & 19.4 \\
\hline 9 & 24 & 8.8 & 11.6 & 15.2 \\
\hline
\end{tabular}

Figure 9 below shows that for every 3 percent increase in silica fume there is a gradual increase in the concrete strength. Moreover the optimum percent replacement of cement with silica fume is found to be 12 percent which gives appreciable result compared to conventional concrete since silica fume acts as an admixture and also as a filler in concrete. It is also observed from the test results that the compressive strength depends on the age of concrete as the age of concrete increases the compressive strength also increases. Comparing the results of control mix and that of optimum replacement level there is a marginal increase in the strength after 7 and 14 days of curing, whereas the compressive strength increases more than 50 percent on testing the cube samples after 28 days when compared with normal mix of concrete which indicates a linear relationship between the age and strength of concrete irrespective of admixture used.

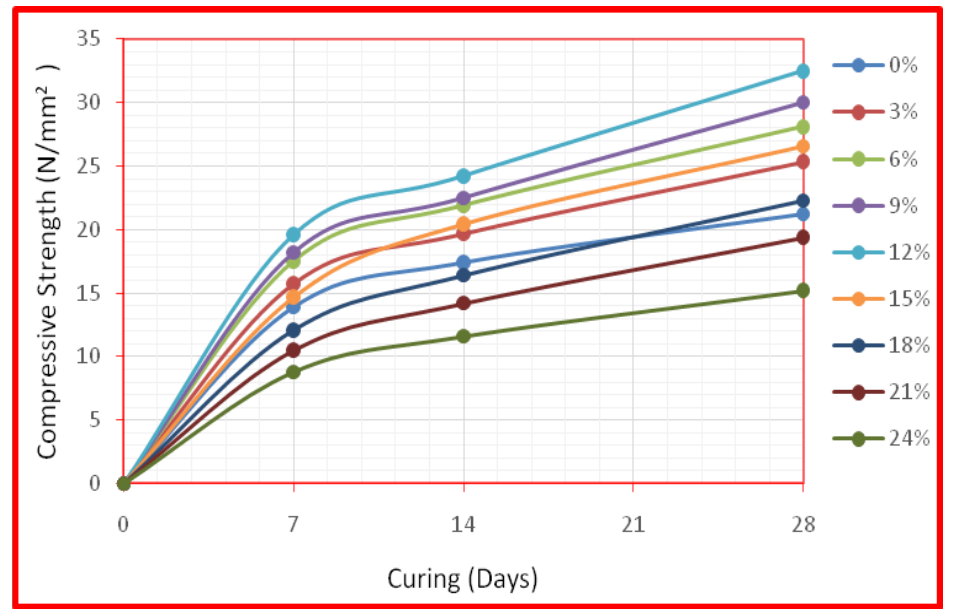

Figure 9. Compressive Strength of Concrete Mix at various proportion of SF

Table 7 shows the test results of M20 grade concrete cubes replacing cement with optimum silica fume and coarse aggregates with reclaimed rubber at 3 percent increments starting from zero until 24 percent.

Table 7: Test Results of M20 Grade Concrete with various proportions of RR and optimum SF

\begin{tabular}{|c|c|c|c|c|}
\hline \multirow{2}{*}{ S.No. } & \multirow{2}{*}{ RR (\%) } & \multicolumn{4}{|c|}{ Average Compressive Strength $\left(\mathbf{N . m m}^{2}\right)$} \\
\cline { 3 - 5 } & & 7 days & 14 days & 28 days \\
\cline { 3 - 5 } & & 13.9 & 17.4 & 21.22 \\
\hline 1 & 0 & 15.72 & 19.65 & 21.78 \\
\hline 2 & 3 & 17.55 & 21.94 & 25.23 \\
\hline 3 & 6 & 19.2 & 23.1 & 29.4 \\
\hline 4 & 9 & 15.54 & 18.3 & 25.7 \\
\hline 5 & 12 & 11.62 & 15.5 & 22.18 \\
\hline 6 & 15 & 9.7 & 11.4 & 20.5 \\
\hline 7 & 18 & 7.56 & 9.2 & 18.16 \\
\hline 8 & 21 & \multicolumn{3}{|c}{} \\
\hline
\end{tabular}




\begin{tabular}{|l|l|l|l|l|}
9 & 24 & 6.06 & 7.31 & 14.3 \\
\hline
\end{tabular}

From the Figure 10 it is evident that the strength increase for a combination of 3 percent RR and optimum SF is meager when compared with control mix, however the strength of concrete increases due to addition of RR which is treated with sodium hydroxide since it improves the bonding between the cement paste and RR in concrete. It can be observed that the maximum strength is attained with a combination of optimum SF and 9 percent RR irrespective of the age of concrete.

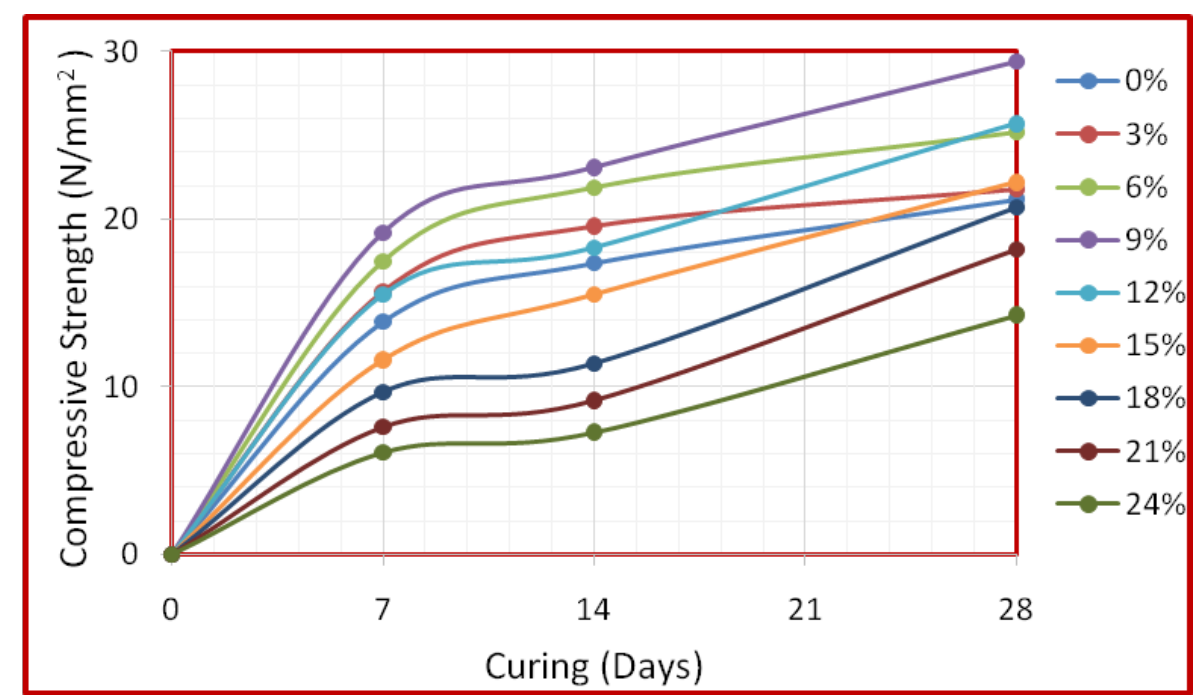

Figure 10. Compressive Strength of Concrete Mix at various proportion of RR and optimum SF

The combined test results (Exp. + GA) for concrete cubes mixed with SF after 28days of curing is shown in Fig.11. The following figure indicates that the curve is non linear up to 12 percent replacement of cement with silica fume in concrete comparing both experimental and analytical results. It is also observed that the results obtained through tests and training of data is linear in nature for various proportions of SF beyond 12 percent replacement level. At the same replacement level (12\%) the experimental results exhibit higher compressive strength than the target strength when compared with analytical results.

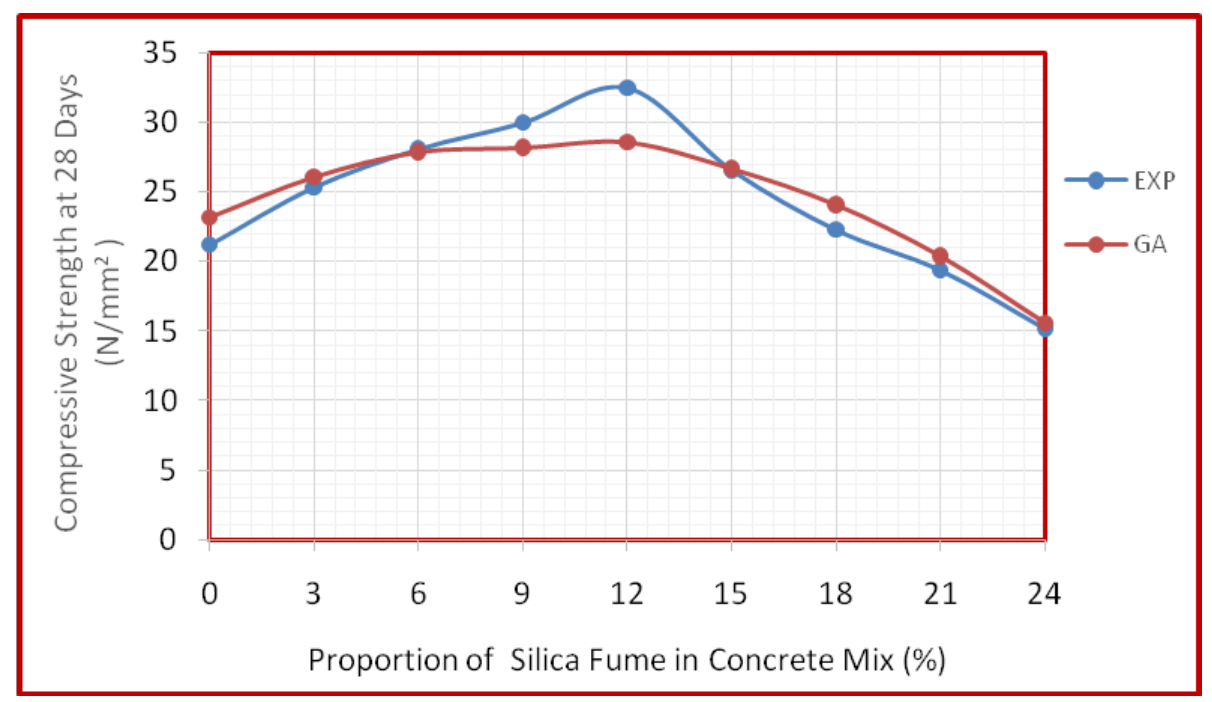

Figure 11. Compressive Strength of Concrete at various proportions of Silica Fume 
The compressive strength of concrete at 28 days is shown in Fig.12 which represents the combined test results of cubes. It is seen that the maximum compressive strength is achieved for a combination of optimum SF and 9 percent replacement of RR in concrete for both values obtained experimentally and using genetic algorithm. From 3 to 9 percent there is an increase in strength and beyond 9 percent RR replacement the compressive strength starts to decrease gradually in analytical result whereas the strength reduces up to 15 percent while testing it using a UTM.

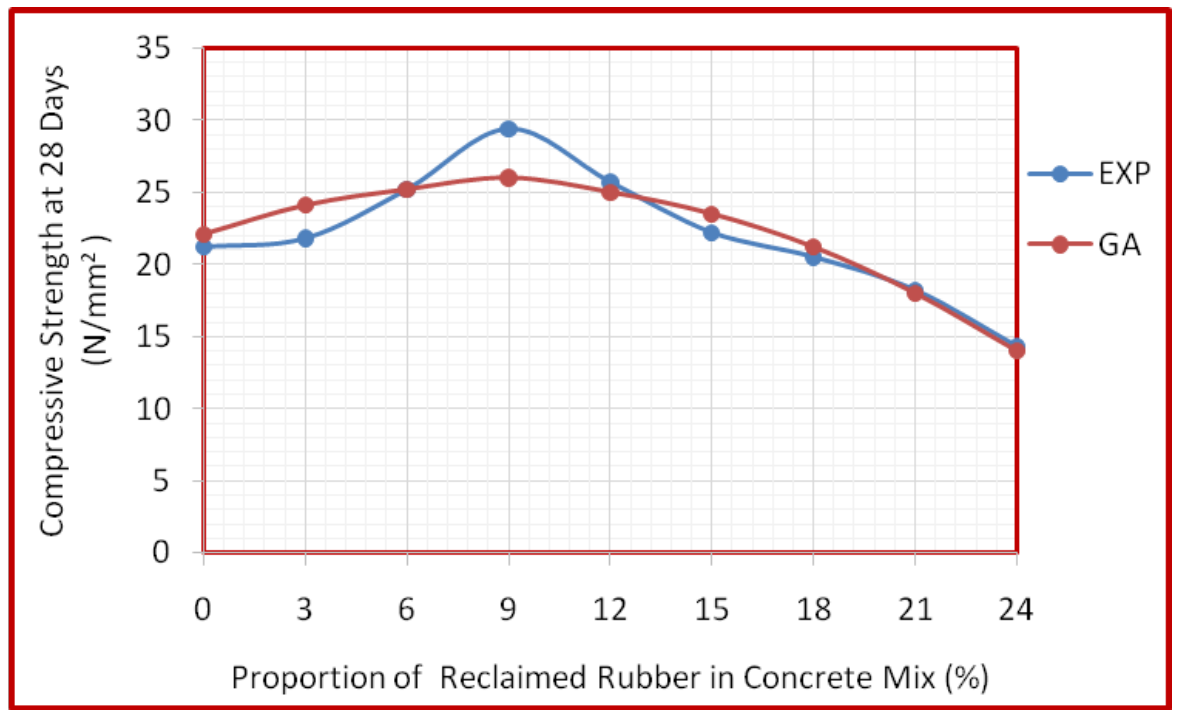

Figure 12. Compressive Strength of Concrete at various proportions of Reclaimed Rubber and Optimum SF

\section{CONCLUSION}

Based on the experimental and analytical results the following conclusions are drawn:

- From the base study it is observed that maximum compressive strength was obtained in concrete mix at 12 percent replacement of cement with silica fume in concrete.

- The target strength of concrete is achieved at 6 percent replacement of silica fume in M20 grade

- Combination of optimum SF (12\%) and 9 percent replacement of coarse aggregates with reclaimed rubber produces better results compared to control mix irrespective of the age of concrete.

- The combination of optimum SF and 9 percent replacement of reclaimed rubber achieves a compressive strength much higher than the target strength.

- Beyond the optimum replacement level of rubber in concrete a further increase in rubber content reduces the compressive strength since the specific gravity of rubber is less than that of conventional aggregates.

$\square \quad$ In the main study it was observed that both experimental and analytical results obtained were similar in magnitude with minor variation irrespective of the material used in concrete mix.

$\square \quad$ It is found that genetic algorithm can be used as an alternative approach for the evaluation of compressive strength of concrete.

$\square \quad$ It is evident from this research that reclaimed rubber may be used as an alternate material replacing conventional aggregates in concrete.

$\square \quad$ It can be concluded that the use of additives influence the properties of concrete to a greater extent irrespective of the concrete grade used in this study.

\section{REFERENCES}

[1] Mansoor and Saravanan, "Experimental Study on Concrete by Partial Replacement of Fine Aggregate with Rubber", International Journals, vol. 1, pp. 60-64, 2015. 
[2] Ahsanul Kabir, Monjurul Hasan and Md. Khasro Miah, "Predicting 28 days Compressive Strength of Concrete from 7 days Test Result", in Proceedings of International Conference on Advances in Design and Construction of Structures, pp. 18-22, 2012.

[3] G.Vaishali Ghorpade, H. Sudharsana Rao and M. Beulah, "Development of Genetic Algorithm Based Neural Network Model for Predicting Workability of High Performance Concrete", International Journal of Research and Reviews in Applicable Mathematics and Computer Science, vol. 2, pp. 40-50, 2012.

[4] Parham Farozani , Ibrahim Ogiri Hassan, Pandian Bothi raja and Mohammed Ismail, " Engineering Behaviour of Recycled Granulated TyreRubber Filled Concrete incorporating Palm oil Fuel Ash ",UTM Construction Research Centre, Malaysia, pp. 1-6,2010.

[5] Debabrata Pradhan and D.Dutta, " Properties Exploration of Conventional Concrete after Silica Supplementation", International Journal of Innovative Research Science Engineering and Technology, vol.3, pp. 8431-8435, 2014

[6] J. Namyong, Y.Sangchun and C. Hongbum," Prediction of Compressive Strength of In-situ concrete based on Mixture Proportions", Journal of Asian Architecture and Building Engineering, vol.3, pp.9-16, 2004.

[7] N.K. Amudhavalli and Jeena Mathew, "Effect of Silica fume on Strength and Durability Parameters in Concrete", International Journal of Engineering Sciences and Emerging Technologies, vol.3, pp. 28-35, 2012.

[8] Aman Sharma, Abhishek Gupta, Vivek Varma and Bhupinder Singh, " Variation of Different percentage of Silica fume on Concrete Mechanical Properties", Inernational Journal of Recent Research Aspects, vol. 1, pp.50-53, 2014.

[9] O.Yousuf, M.A.El Gawady,J.E.Mills and X.Ma, “ Prediction of Crumb Rubber Concrete Strength", Australasian Conference on the Mechanics of Materials and Structures, December, 2014.

[10] Morteza Khorammi, Abolhasan Vafai and A.Ahmad Khalilitabas, "Experimental Investigation on Mechanical Characteristics and Environmental Effects on Rubber Concrete", International Journal of Concrete Structures and Materials., vol. 4, pp. 17-23, 2010.

[11] Moayyad Al Nassra and Zeljko Torbica, " Concrete made for Energy Conservation using Recycled Rubber Aggregates", International Journal of Engineering Science Invention, vol. 2, pp.10-16, 2013.

[12] Zeineddine Boudaoud and Miloud Beddar, " Effects of Recycled Tyre Rubber Aggregates on the Characteristics of Cement Concrete", Open Journal of Civil Engineering, vol. 2, pp. 193-197,2012.

[13] A.Ahangar, A.Faramarzi and A.A.Javadi, "An Evolutionary Numerical Approach to modelling the Mechanical Properties of Rubber Concrete", Proceedings of the International Conference of Computing in Civil and Building Engineering, pp. 411-416, 2010.

[14] C. H.Aginam, C.A.Chidolue and C. Kwakire, " Investigating the Effects of Coarse Aggregate Types on the Compresive Strength of Concrete", International Journal of Engineering Research and Applications, vol. 3, pp. 1140-1144, 2013.

[15] Pratik Patel and Indrajit Patel, " Effect of partial Replacement of Cement with Silica fume and Celluose Fiber on Workability and Compressive Strength of High Performance Concrete", Indian Journal of Applied Research, vol.3, pp. 263-264, 2013. 